\title{
Controlled Expansion of Bone and Accurate Implant Placement Using an Acrylic Stent and Surveyor
}

\author{
Aditya Mani ${ }^{1}$ and Punit Naidu ${ }^{2 *}$ \\ ${ }^{1}$ Private Practitioner, Hyderabad, India \\ ${ }^{2}$ Consultant, Apollo Hospitals, Hyderabad, India \\ *Corresponding Author: Punit Naidu, Consultant, Apollo Hospitals, \\ Hyderabad, India.
}

Received: April 08, 2020

Published: May 20, 2020

(C) All rights are reserved by Aditya Mani and Punit Naidu.

\begin{abstract}
Ridge expansion is a technique used to increase the buccolingual dimension in deficient bone so that it allows the placement of an adequately sized implant in a favourable angulation and position to enhance the biomechanical and prosthetic success [1]. The inherent elasticity of the maxillary bone lends itself more easily to this procedure than the denser mandibular bone. In this case report, a clinical case, which presented itself with deficient bone in the maxillary anterior region has been discussed. Other techniques of augmenting resorbed bone include distraction osteogenesis, onlay grafts, guided bone regeneration and ridge split. However, these procedures are not only more invasive but also present themselves with the requirement of an additional donor site, with added morbidity [2]. In carefully selected cases, gentle and controlled ridge expansion with osteotome has a high predictability and also negates the morbidity associated with a donor site.
\end{abstract}

Keywords: Bone; Implant Placement; Acrylic Stent

\section{Introduction}

It is well accepted that alveolar bone loss occurs rapidly after tooth extraction. A $25 \%$ decrease in the crestal bone width may be observed in the first year. $40 \%$ of the bone width may be lost in 1 3 years [3]. Gentle ridge expansion techniques are beneficial when the deficiency in the bone volume in the buccolingual direction isn't too great and there isn't any vertical bone deficiency. In cases with substantial bone resorption, other methods of bone augmentation such as onlay graft and ridge splits may be used. Also, ridge expansion techniques are especially useful to enhance the emergence profile of the implant crown.

\section{Case Report}

A 25 year old male patient reported with a chief complaint of missing upper front tooth. On intraoral examination, maxillary lateral incisor was found to be missing on the left side.

A complete case history was recorded and examination was performed. Diagnostic models were made. An orthopantomogram and blood investigations was also requested. The findings of the investigations were discussed with the patient and treatment options were presented. Implant therapy was agreed upon and written informed consent was obtained from the patient. Though the

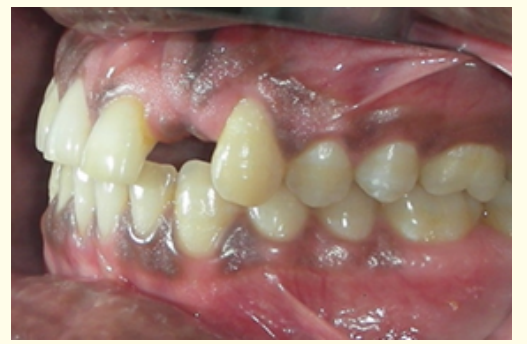

Figure 1: Missing maxillary lateral incisor.

available bone volume was adequate for the placement of a regular platform implant, it was decided to gently expand the ridge to improve the emergence profile of the implant crown. A surgical stent was fabricated which would guide the implant placement in the correct angulation (Figure 2). This was done as follows: The diagnostic models were sectioned using the pindex system and mounted on the Jelenko surveyor. The undercuts were blocked on the labial side. An acrylic stent (using DPI self-polymerizing resin) was fabricated from left maxillary canine to right lateral incisor on the contralateral side (Figure 3 and 4). 


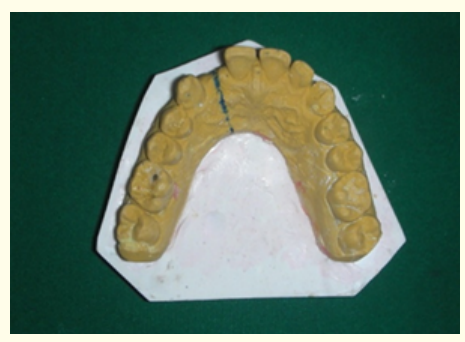

Figure 2: Fabrication of surgical stent.

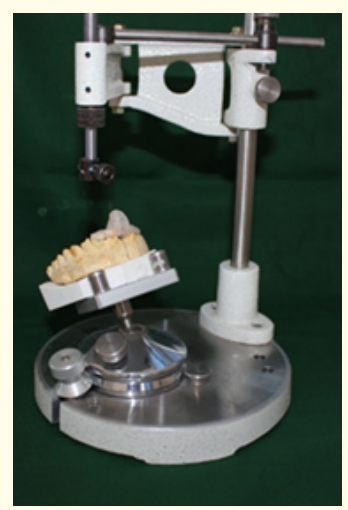

Figure 3: Fabricated chairside intraoral stent on Jelenko surveyor.

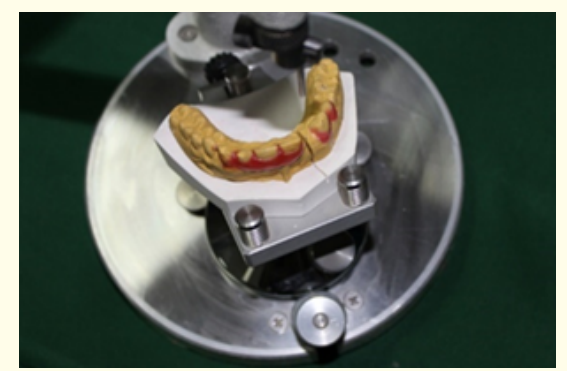

Figure 4: Undercuts blocked on labial side.

Ridge mapping was performed with the help of an acrylic stent and an endodontic file to accurately estimate the mucosal thickness and the bone volume of the edentulous site (Figure 5 and 6).

These markings were transferred from the ridge onto a butter paper. They were further transferred on a graph sheet to accutarely measure the dimension of the bone volume in the edentulous site (Figure 7 and 8).

Once the dimension of available bone is estimated and the marked on the butter paper, dots are placed $1 \mathrm{~mm}$ from the margin.

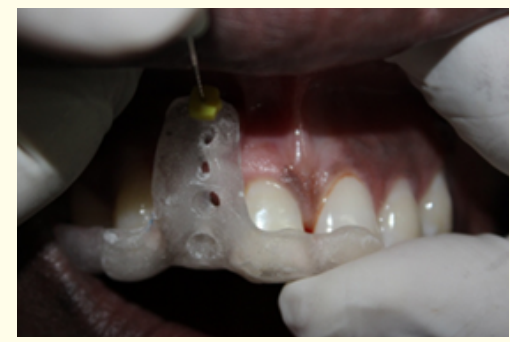

Figure 5: Acrylic stent fabricated from left canine to right central incisor for bone sounding.

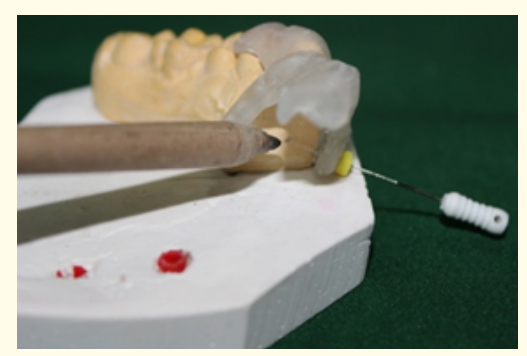

Figure 6: Ridge mapping with the help of endodontic file and acrylic stent.

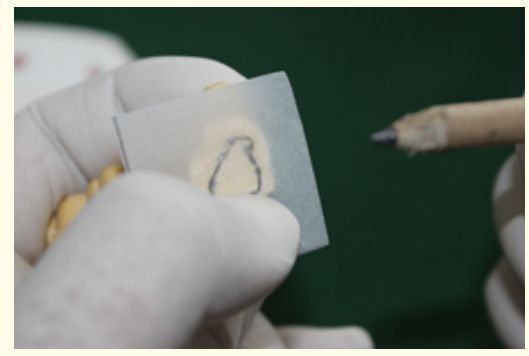

Figure 7: Transferring of markings on paper.

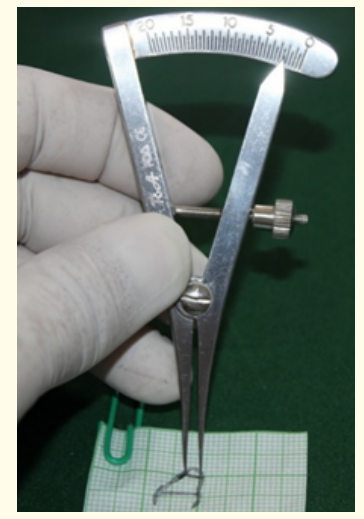

Figure 8: Transferring of marking on graph paper. 
The space between the dots marks the amount of cancellous bone present where the osteotomes were inserted to allow controlled expansion of bone (Figure 9).

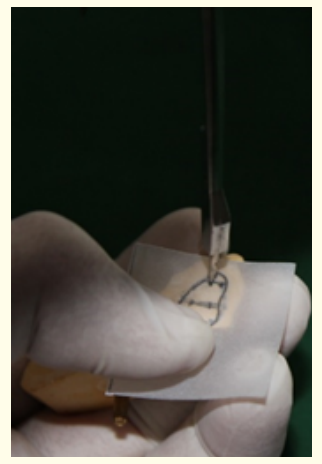

Figure 9: Marking with analysing rod.

The analysing rod, which was the same diameter as the pilot drill was placed in the same inclination as the implant to be placed.

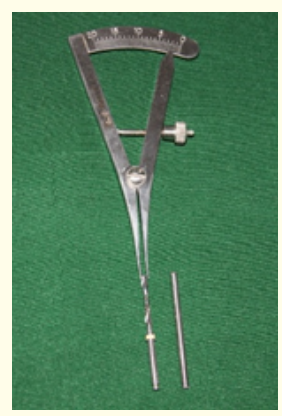

Figure 10: Pilot drill $2 \mathrm{~mm}$.

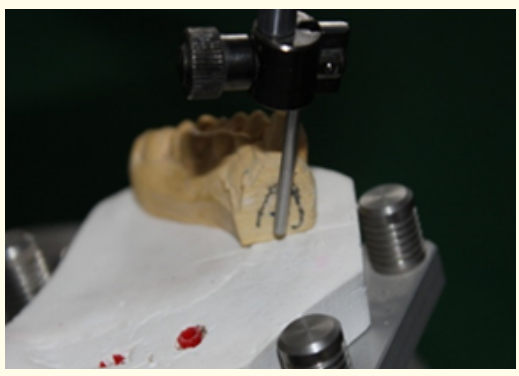

Figure 11: Metal rod to create access hole - $2 \mathrm{~mm}$.

The analysing rod was coated with vaseline and was secured to the stent with clear acrylic. The stent was perforated where the analysing rod was touching it. This served as a guide for the osteo- tome to carefully engage the cancellous bone and expand the labial cortical plate without fracturing it (Figure 12 and 13).

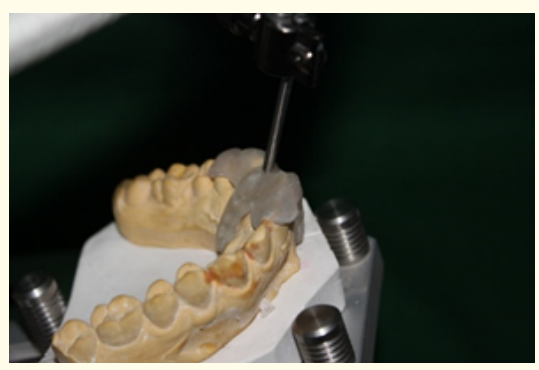

Figure 12: Perforation of acrylic stent with analysing rod.

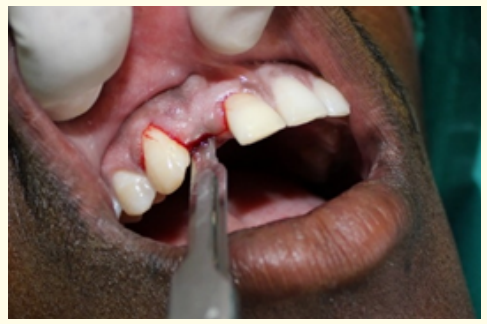

Figure 13: Crestal incsion right maxillary region.

Osteotomy site was prepared, and a hand osteotome was used to carefully expand the labial cortical plate and condense the bone particles in the implant site (Figure 14). The ability of osteotomes to manipulate and compress existing bone without generating heat makes them particularly useful for expanding narrow ridges and densification of bone around the osteotomy [4]. This may lead to increased primary stability of the implant fixture at the time of implant placement.

Following this, adin implant was placed and torqued to $40 \mathrm{Ncm}$. The site was sutured with non resorbable surgical black braided silk suture (Figure 16 and 17).

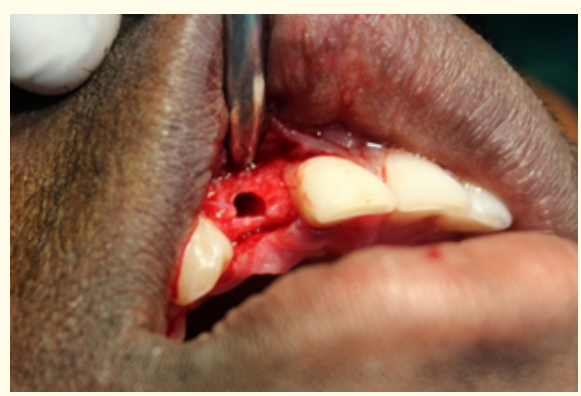

Figure 14: Osteomy site prepared. 


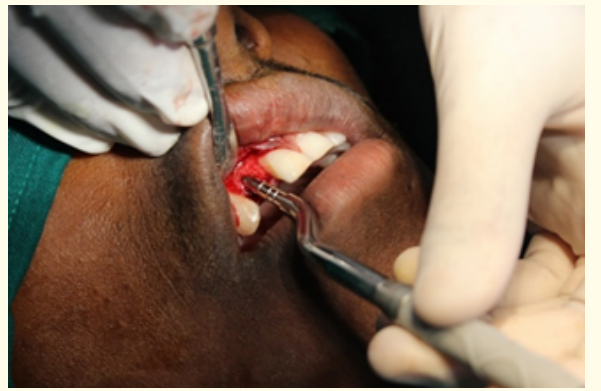

Figure 15: Hand osteotome to expand labial cortical plate.

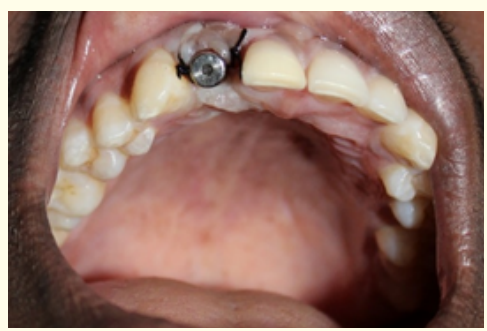

Figure 16: Adin placement and sutured the surgical site.

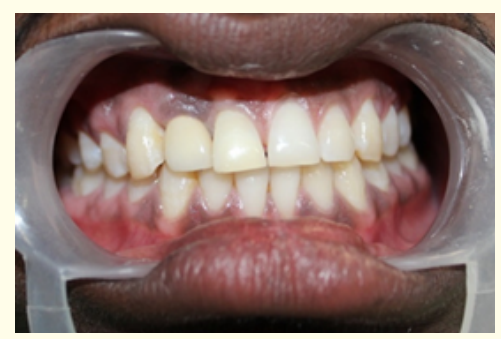

Figure 17: Healing after 6 months provisional restoration given.

\section{Discussion}

Implant placement is prosthetically driven. The position and angulation of implants should be such that it allows the masticatory forces to be applied along the long axis of the implant fixtures. Malaligned implants often complicate the clinical laboratory procedures employed for fabrication of superstructures. Due to improper load distribution, an overall increase in stress concentration on supporting structures may occur. This may compromise the maintenance of the bone implant interface [5].

Undoubtedly, the use of CBCT technology/tomographic imaging has a very important place in implant dentistry. The volume of compact and cancellous bone as well as presence of anatomic limitations can be very well determined by CBCT. However, it may not be feasible to procure a CBCT in every case due to the added ex- penditure to the patient. In these situations, the use of surveyor and the surgical guide stent, as has been discussed in this case report can largely aid in controlled bone expansion and implant placement [6-10].

\section{Conclusion}

Controlled and gentle ridge expansion techniques with osteotomes can be immensely helpful to restore narrow ridges, not less than $4 \mathrm{~mm}$ in width and to improve the emergence profile of the implant crowns. The use of a surveyor and a surgical stent to guide the osteotomy, as has been discussed in the case presented is a costeffective alternative to the use of traditional tomographic imaging. The osteotomes serves to condense and compress the bone around the osteotomy site, thereby enabling greater stability of the implant fixture.

\section{Bibliography}

1. Len Tolstunov and Bruce Hicke. "Horizontal Augmentation Through the Ridge-Split Procedure: A Predictable Surgical Modality in Implant Reconstruction". Journal of Oral implantology 39.1 (2013): 59-61.

2. Aghaloo TL and Moy PK. "Which hard tissue augmentation techniques are the most successful in furnishing bony support for implant placement?" International Journal of Oral and Maxillofacial Implants 22 (2007): 49-70.

3. Goyal S and Iyer S. "Bone manipulation techniques". International Journal of Clinical Implant Dentistry 1.1 (2009): 22-31.

4. Benjamin A Baptist. "Clinical Applications of an Atraumatic Osteotome”. Compendium 38.8 (2017): 538-543.

5. Kıvanç Akça., et al. "A surgical guide for accurate mesiodistal paralleling of implants in the posterior edentulous mandible". Journal of Prosthetic Dentistry 87.2 (2002): 233-235.

6. Byju Paul Kurian., et al. "Osteotome assisted maxillary ridge expansion with implant placement: A case report". The Journal of Prosthetic and Implant Dentistry 1.2 (2018): 81.

7. US Pal., et al. "Role of surgical stents in determining the position of implants". National Journal of Maxillofacial Surgery 1.1 (2010): 20-23.

8. Yuvika Mittal., et al. "Bone manipulation procedures in dental implants”. Indian Journal of Dentistry 7.2 (2016): 86-94.

9. Jack Hahn. "Clinical use of osteotomes". Journal of Oral Implantology 25.1 (1999): 23-29. 
10. Saad Al-Almaie. "Osteotome-Assisted Lateral Bone Expansion and Condensation with Immediate Dental Implants Placements".

\section{Assets from publication with us}

- Prompt Acknowledgement after receiving the article

- Thorough Double blinded peer review

- Rapid Publication

- Issue of Publication Certificate

- High visibility of your Published work

Website: www.actascientific.com/

Submit Article: www.actascientific.com/submission.php

Email us: editor@actascientific.com

Contact us: +919182824667 